Article

\title{
Inhibiting the Segregation of Germanium in Silver Nanolayers
}

\author{
Arkadiusz Ciesielski ${ }^{1, * \mathbb{D}}$, Marek Trzcinski ${ }^{2}$ and Tomasz Szoplik ${ }^{1}(\mathbb{D}$ \\ 1 Faculty of Physics, University of Warsaw, Pasteura 5 str., 02-093 Warsaw, Poland; tszoplik@mimuw.edu.pl \\ 2 Institute of Mathematics and Physics, UTP University of Science and Technology, Kaliskiego 7 Str. \\ 85-796 Bydgoszcz, Poland; marekt@utp.edu.pl \\ * Correspondence: aciesiel@igf.fuw.edu.pl
}

Received: 12 February 2020; Accepted: 24 March 2020; Published: 1 April 2020

\begin{abstract}
It is generally acknowledged that using germanium as a wetting film for silver nanolayers decreases the surface roughness of the metal. However, germanium atoms also tend to segregate towards the surface of silver films, increasing ohmic losses in the structure. Here we propose an $\mathrm{Au} / \mathrm{Ge} / \mathrm{Ag}$ based structure where the segregation of germanium in silver is inhibited. X-ray photoelectron spectroscopy (XPS) results show that for the $\mathrm{Au} / \mathrm{Ge} / \mathrm{Ag}$ system, the surface concentration of germanium drops by an order of magnitude relative to multilayers containing only one type of metal (Ag or $\mathrm{Au})$. We have also observed that the time-dependent decrease in the reflectivity due to localized surface plasmon excitation is less prominent in the case of the $\mathrm{Au} / \mathrm{Ge} / \mathrm{Ag}$ structure than in the case of $\mathrm{Ag} / \mathrm{Ge} / \mathrm{Ag}$. We provide XPS as well as optical reflectometry results to support that claim.
\end{abstract}

Keywords: silver; germanium; gold; nanolayers; segregation

\section{Introduction}

Metal nanolayers, as carriers of surface plasmon waves, may be used in plasmonic, biosensor and functional material applications, provided that they exhibit minimal ohmic and scattering losses [1-8]. Since silver and gold have the smallest imaginary part of permittivity within the visible frequency range, they are routinely applied in plasmonic devices. However, in the nanoscale, poor adhesion of silver to commonly used substrates such as ultra-smooth fused silica or sapphire results in a rough metal-free surface, which increases the scattering losses of the metal film. To tackle this problem, a number of approaches have been proposed, the most prominent being the use of wetting materials exhibiting good adhesion to both silver and the substrate [9-24]. The greatest reduction of surface roughness - up to an order of magnitude - is observed when the substrate is wetted with a 2-nm-thick layer of germanium prior to the deposition of silver $[2,11]$. This approach considerably reduces the scattering losses of silver films, but has one significant drawback-over time, germanium atoms segregate through silver grain boundaries towards the free surface of the metal [19]. This results in the formation of Ge-encapsulated silver grains near the film's surface which gives rise to interesting optical phenomena like additional plasmonic absorption or strong Second Harmonic Generation (SHG) enhancement [7]. Additionally, this effect substantially increases ohmic losses of the silver films, ultimately excluding such layers from many potential applications [18,25-27].

Physical phenomena at the interfaces of sandwich-like structures composed of an insulating substrate, elemental semiconductor and noble metal have been experimentally studied and considered in thermodynamic models for a few decades [28-41]. Surface segregation and grain boundary segregation of foreign atoms in a solid solvent considerably influence its dielectric functions and are of great importance in metallurgy and materials science in general [42-44]. 
It has previously been demonstrated that Ge atoms segregate to the surface of Ag and Au layers deposited on germanium wetting films, even in case of metal/Ge/metal sandwich structures $[37,38,40]$. Such behavior is attributed to non-uniform metal grain size distribution within the depth of the film, as evidenced by X-Ray Reflectometry measurements [37,40]. Ge atoms present in the sub-surface metal grain boundaries separate the metal grains electrically, increasing their ohmic losses $[18,19,40]$ and allowing for localized surface plasmon excitation [7,37,38,40,41]. Excitation of surface plasmons on Ge-covered metal grains contributes to lower reflectivity in the visible range [7].

For many applications, like biosensing or information transfer, the effects of surface segregation might be detrimental. In order to avoid Ge segregation in silver, Wróbel et al. [19], proposed to cover the silver film with an $\mathrm{Al}_{2} \mathrm{O}_{3}$ capping layer. Alumina migrates within the silver layer through grain boundary diffusion, essentially making Ag grain boundaries inaccessible to germanium atoms. This approach is very effective; however, in the case of devices such as biosensors where the silver layer has to be covered with a specific compound, it cannot be applied. In this work, we propose a different approach. Instead of covering the silver layer with a material which exhibits grain boundary diffusion within silver, we introduce another layer below germanium, which is made of gold. Germanium has been proven to segregate within the nanolayers of both silver and gold [11-27], as Ag and Au exhibit many crucial similarities, like their atomic radius and lattice constant. However, the free enthalpy of the segregation process is influenced by many quantities in which silver and gold differ-e.g., bulk modulus, shear modulus and surface energies [28,42]. Moreover, the segregation process might also be influenced by differences in the adhesion forces and mutual solubilities in the $\mathrm{Ge}-\mathrm{Ag}$ and $\mathrm{Ge}-\mathrm{Au}$ systems.

Here, we report on X-ray photoelectron spectroscopy (XPS) and reflectometry measurements of metal/Ge/metal (where the metal is $\mathrm{Ag}$ or $\mathrm{Au}$ ) sandwich structures to show an inhibited surface segregation of germanium in an $\mathrm{Au} / \mathrm{Ge} / \mathrm{Ag}$ system relative to other investigated systems. We attribute this effect partially to the differences in bulk and shear moduli as well as surface energies of the metal layers. To the best of our knowledge, segregation in such a structure has never been investigated before.

\section{Materials and Methods}

All of the investigated layers were deposited using a PVD75 e-beam evaporation system from Lesker. The samples were deposited on $\mathrm{SiO}_{2}$ substrates with the Root-Mean-Square (RMS) roughness parameter equal to $0.3 \mathrm{~nm}$, located $40 \mathrm{~cm}$ away from the crucibles. The evaporation materials, $5 \mathrm{~N}$ germanium, $4 \mathrm{~N}$ silver and $4 \mathrm{~N}$ gold, were placed in tungsten or Fabmate crucibles and evaporated using a beam of electrons accelerated by an $8 \mathrm{kV}$ bias. The deposition rates were $0.5 \AA / \mathrm{s}, 2 \AA / \mathrm{s}$ and $2 \AA / \mathrm{s}$ for germanium silver and gold, respectively. To avoid surface corrosion, all samples were covered by a 3-nm-thick LiF capping layer formed by the evaporation of $3 \mathrm{~N} \mathrm{LiF}$ at an average rate of $1 \AA / \mathrm{s}$ from a tungsten crucible. The base pressure was set to $2 \times 10^{-5}$ Torr in the vacuum chamber and did not exceed $5 \times 10^{-5}$ Torr during the deposition process. The final film thickness and deposition rate were monitored by two quartz weights inside the deposition chamber. Thicknesses of the acquired films were verified by Dektak $6 \mathrm{M}$ stylus profiler. All samples were deposited at room temperature. No significant temperature increase during the fabrication process was observed-the difference between initial temperature and final temperature did not exceed $5 \mathrm{~K}$.

XPS spectra were obtained by VG Scienta R3000 hemispherical analyzer (Uppsala, Sweden). The main axis of the analyzer was aligned with the normal of the sample. The radiation source with aluminum anode $(\mathrm{Al} \mathrm{K} \alpha, \hbar \omega=1486.6 \mathrm{eV})$ was oriented at 55 degrees relative to the normal of the sample. The base pressure of the analysis chamber was $\leq 2 \times 10^{-10} \mathrm{mbar}$. In an attempt to perform a depth profile and obtain XPS data from the area below the surface, the sample was subjected to argon ion sputtering. The energy of ions was $4 \mathrm{keV}$ and the incident angle was $69^{\circ}$. To assure relatively uniform etching of the surface, the ion beam was set to scan $4 \times 4 \mathrm{~mm}$ area of the sample. The ion sputtering operated for $2 \mathrm{~min}$. After that, another set of spectra were recorded and the whole process repeated. In order to evaluate the atomic concentrations, the spectra for the most intensive peaks of components present in the sample were fitted to Gauss-Lorentz shapes using CasaXPS ${ }^{\circledR}$ 
software version 2.3.16 (Casa Software Ltd, Teignmouth, UK). Then, the area under the fitted curves was normalized to the relative sensory factor for each element and compared to the total area for all investigated peaks for all elements, to obtain the atomic concentration for each element after each etching step. A more detailed example of acquiring the atomic concentration values and Ge-to-metal ratios can be found in the Supplementary Materials.

Reflectivity measurements were performed using an F3-UV device (Filmetrics, USA) in the normal incidence-normal collection configuration justified for smooth surface characterization.

\section{Results and Discussion}

Figure 1a presents survey XPS spectra collected from the very surface of sandwich samples, where a 2-nm-thick layer of germanium is deposited between 20-nm-thick layers of silver and gold. The XPS spectra were collected 30 days after the fabrication of the samples, to allow germanium to fully segregate towards the surface [37]. For comparison, the spectra for sandwich-like structures where the germanium is deposited between two layers of the same metal, measured 10 days after sample fabrication, from works [38,39], are also presented. A germanium $2 p$ doublet is clearly visible for all the samples on the slope of the inelastic background-above $1200 \mathrm{eV}$-proving the segregation of this element towards the surface. Aside from this, strong signals from $\mathrm{Ag}$ and $\mathrm{Au}$ are also present (main doublets at about 370 and $85 \mathrm{eV}$, respectively), as well as the sharp peak originating from fluorine at $685 \mathrm{eV}$, since the samples were covered with a thin protective LiF layer. Lithium, as a very light element, is poorly detectable by XPS technique. Its relative sensitivity factor (RSF) is lower than 0.06 (while carbon has an RSF $=1$ ) and its peak expected at $55 \mathrm{eV}$ is obscured by the background noise. Samples were kept out of vacuum before XPS measurements; therefore, the peaks of most common contaminants—oxygen at $531 \mathrm{eV}$ and carbon at $285 \mathrm{eV}$-are also present in all spectra. As mentioned before, the Ge2 $p_{3 / 2}$ and Ge2 $p_{1 / 2}$ peaks—at 1220 and $1251 \mathrm{eV}$, respectively-are present on all of the depicted spectra, but for the sandwich where the Ag layer is at the top and the Au layer at the bottom, this signal is significantly less intense. This suggests that a smaller amount of germanium is present at the surface and therefore indicates a lower segregation rate. This might be due to the difference in specific interactions of Ge-to-Au and Ge-to-Ag, which contribute towards partial thermodynamic potentials of the migration process, like the enthalpy of mixing $[45,46]$. Moreover, the differences in bulk modulus, shear modulus and the surface energies of silver and gold contribute to the enthalpy of the segregation of Ge in Ag and Ge in Au [28,42] This, in turn, influences the adhesion force and mutual solubilities of the two elements. The effect is preserved even if an additional Ge wetting layer is deposited at the substrate/metal interface, which not only doubles the amount of germanium in the system, but induces a gradient change in the crystallinity profile of the bottom gold layer, which should promote the segregation of germanium towards the surface $[38,40,41]$. This result is depicted in Figure 1b. Even in this case, the Ge signal in the XPS spectrum is much weaker than for the sample not containing gold. However, in the case where the bottom metal layer is made of silver and the top is made of gold, the Ge signal in the XPS spectrum is very prominent. 

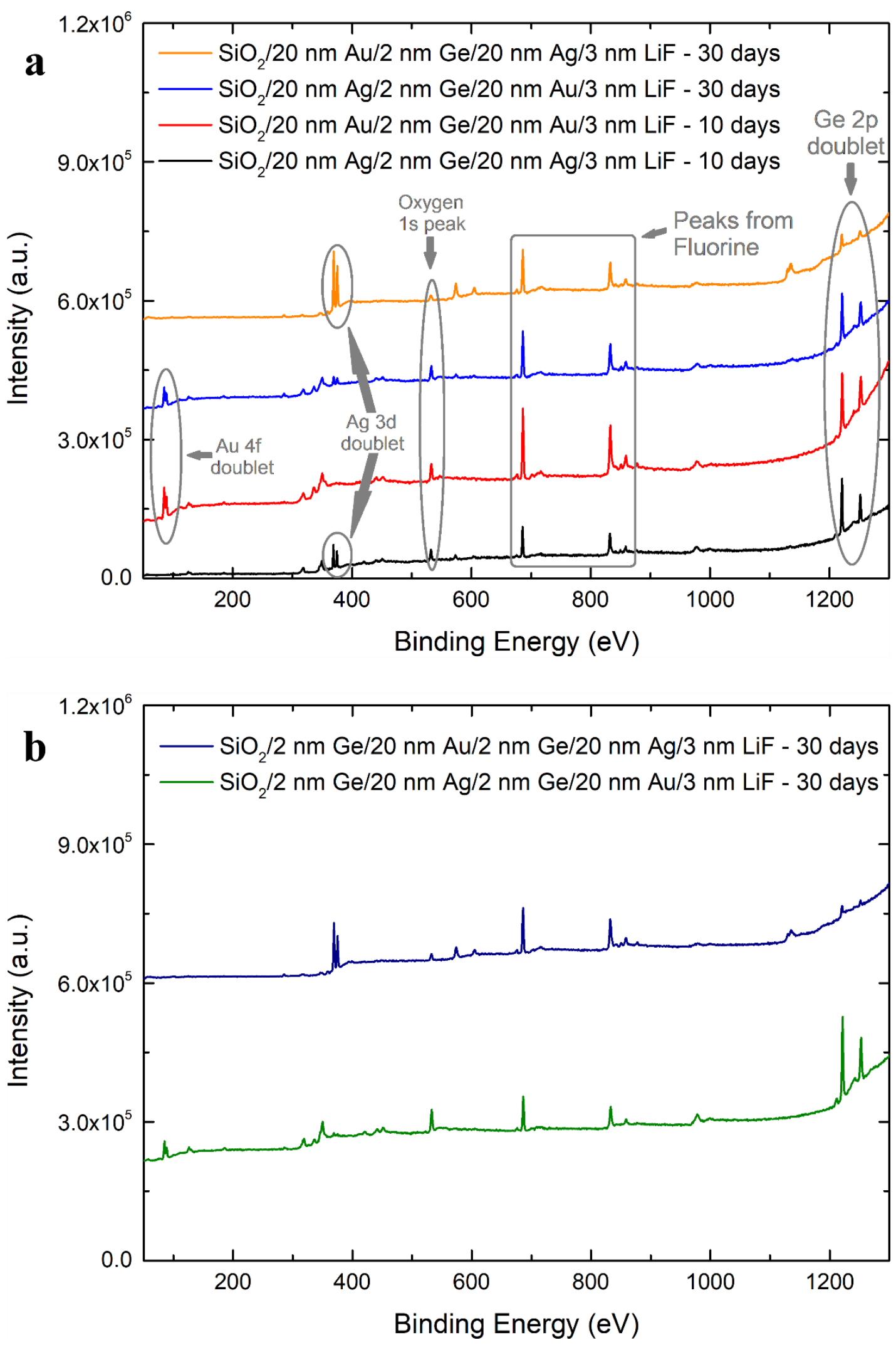

Figure 1. (a) X-ray photoelectron spectroscopy (XPS) spectra of sandwich-like structures where 2-nm-thick germanium film is deposited in between 20-nm-thick Ag and Au layers, when the Au is at the bottom (orange curve) or at the top (blue curve). For comparison, spectra for structures where the germanium is deposited between two layers of the same metal, from refs [38,39], are also presented. (b) XPS spectra of similar structures, but with an additional Ge film at the substrate/metal interface. The intensity curves on both figures are offset by different values for clarity of reading. 
To quantify the atomic concentrations of particular elements on the surface, the CasaXPS ${ }^{\circledR}$ software was used to fit the XPS data peaks to the Gauss-Lorentz shapes. Assuming knowledge about the origin of all peaks, and considering the relative sensitivity factor (RSF) for each element, it is possible to calculate the atomic concentration of each element on the surface by integrating the area under those peaks. Then, by dividing the concentration of germanium by the concentration of metal, we obtained the Ge-to-metal ratio. The values are presented in Table 1. For the $\mathrm{Ag} / \mathrm{Ge} / \mathrm{Ag}$ sample, the $\mathrm{Ge}-$ to-metal ratio equals 1.77 , which is $62 \%$ greater than for a similar sample with both metal layers made of Au. This indicates that germanium in gold segregates at a slower pace than in silver, which is most likely due to the larger grain size of gold layers with similar thickness. This matter is discussed in detail elsewhere [40]. However, when the bottom metal layer is made of silver, and the top metal layer is made of gold $(\mathrm{Ag} / \mathrm{Ge} / \mathrm{Au})$, and enough time is given for the Ge atoms to segregate towards the sample surface, the Ge-to-metal ratio increases to 1.63 , which is very similar to the 1.77 in the case of the $\mathrm{Ag} / \mathrm{Ge} / \mathrm{Ag}$ sample. This suggests that the adhesion force of germanium to gold is stronger than that of germanium to silver, since most of Ge atoms migrate towards the top Au interface rather than the bottom Ag one. Moreover, the fact that that the Ge-to-metal ratio values differ by only $8 \%$ suggests that, for the investigated amount of germanium in the system, the thermodynamic equilibrium on the surface is reached when the number of Ge atoms is approximately $70 \%$ greater than the number of metal atoms.

Table 1. Surface Ge-to-metal ratios calculated from the XPS spectra prior to any ion etching for all measured samples.

\begin{tabular}{|c|c|}
\hline Sample & Surface Ge-to-Metal Ratio \\
\hline $\begin{array}{c}\mathrm{SiO}_{2} / 20 \mathrm{~nm} \mathrm{Ag} / 2 \mathrm{~nm} \mathrm{Ge} / 20 \mathrm{~nm} \mathrm{Ag} / 3 \mathrm{~nm} \mathrm{LiF} \text { (measured } 10 \text { days after } \\
\text { deposition) }\end{array}$ & 1.77 \\
\hline $\begin{array}{c}\mathrm{SiO}_{2} / 20 \mathrm{~nm} \mathrm{Au} / 2 \mathrm{~nm} \mathrm{Ge} / 20 \mathrm{~nm} \mathrm{Au} / 3 \mathrm{~nm} \mathrm{LiF} \text { (measured } 10 \text { days after } \\
\text { deposition) }\end{array}$ & 1.09 \\
\hline $\begin{array}{c}\mathrm{SiO}_{2} / 20 \mathrm{~nm} \mathrm{Ag} / 2 \mathrm{~nm} \mathrm{Ge} / 20 \mathrm{~nm} \mathrm{Au} / 3 \mathrm{~nm} \mathrm{LiF} \text { (measured } 30 \text { days after } \\
\text { deposition) }\end{array}$ & 1.63 \\
\hline $\begin{array}{c}\mathrm{SiO}_{2} / 20 \mathrm{~nm} \mathrm{Au} / 2 \mathrm{~nm} \mathrm{Ge} / 20 \mathrm{~nm} \mathrm{Ag} / 3 \mathrm{~nm} \mathrm{LiF} \text { (measured } 30 \text { days after } \\
\text { deposition) }\end{array}$ & 0.19 \\
\hline $\begin{array}{c}\mathrm{SiO}_{2} / 2 \mathrm{~nm} \mathrm{Ge} / 20 \mathrm{~nm} \mathrm{Ag} / 2 \mathrm{~nm} \mathrm{Ge} / 20 \mathrm{~nm} \mathrm{Au} / 3 \mathrm{~nm} \mathrm{LiF} \text { (measured } 30 \text { days } \\
\text { after deposition) }\end{array}$ & 3.07 \\
\hline $\begin{array}{c}\mathrm{SiO}_{2} / 2 \mathrm{~nm} \mathrm{Ge} / 20 \mathrm{~nm} \mathrm{Au} / 2 \mathrm{~nm} \mathrm{Ge} / 20 \mathrm{~nm} \mathrm{Ag} / 3 \mathrm{~nm} \mathrm{LiF} \text { (measured } 30 \text { days } \\
\text { after deposition) }\end{array}$ & 0.18 \\
\hline
\end{tabular}

However, in the $\mathrm{Au} / \mathrm{Ge} / \mathrm{Ag}$ configuration, the surface Ge-to-metal ratio drops more than nine times, to 0.19 atoms of germanium per 1 atom of metal. The same is true for a similar sample with an additional $\mathrm{Ge}$ film at the substrate/metal interface $(\mathrm{Ge} / \mathrm{Au} / \mathrm{Ge} / \mathrm{Ag})$. Its presence-as mentioned in an earlier section - changes the density profile of the bottom metal layer in a way that should promote the segregation of Ge atoms to the surface of the sample [38,40,41], yet the surface Ge-to-metal ratio is exceptionally similar-only 0.18 . On the other hand, in the $\mathrm{Ge} / \mathrm{Ag} / \mathrm{Ge} / \mathrm{Au}$ sample, the Ge-to-metal concentration ratio at the surface increases almost twice relative to $\mathrm{Ag} / \mathrm{Ge} / \mathrm{Au}$ sample, which is not surprising considering the double amount of germanium in a sample with a configuration that allows for the segregation process to progress. Therefore, we conclude that the adhesion forces and the enthalpy of mixing are greater in the $\mathrm{Ge}-\mathrm{Au}$ system than in the $\mathrm{Ge}-\mathrm{Ag}$ system.

To investigate the full concentration profile of germanium atoms as a function of subsurface depth in the $\mathrm{Au} / \mathrm{Ge} / \mathrm{Ag}$ sample, we have performed a series of XPS measurements interlaced with $\mathrm{Ar}^{+}$ion etching and determined the concentration of Ge atoms for each collected spectrum. The results are plotted in Figure 2. For a typical sample, where most of Ge atoms have segregated to the surface, the atomic concentration of germanium should be the greatest after 1-2 min of etching and then 
it should monotonously decrease with etching time $[38,40]$. In the case of the $\mathrm{Au} / \mathrm{Ge} / \mathrm{Ag}$ sample, the surface still exhibits the highest concentration of Ge atoms with respect to all subsurfaces (except for the spectrum collected prior to any ion etching, where lithium and fluorine from the LiF film as well as adventitious carbon and oxygen adsorbed from air are also detected). This means that the Ge surface segregation, although inhibited, is not canceled completely. However, the Ge concentration profile is not monotonous, as would be expected form a typical sample in which Ge atoms segregate. Instead, after $8 \mathrm{~min}$ of etching, which essentially represents the middle of the sample (and thus, the depth that the Ge was deposited at) there is another maximum. This implies that a lot of atoms still reside at the boundary of Ag and Au films. After further etching, the concentration of germanium drops slowly, which suggests that some germanium atoms have migrated towards the gold/substrate interface through Au grain boundary diffusion. We conclude that due to high adhesion of Ge to Au, there is a smaller energy benefit of germanium atoms segregating to the surface than in the case of samples without the bottom Au layer.

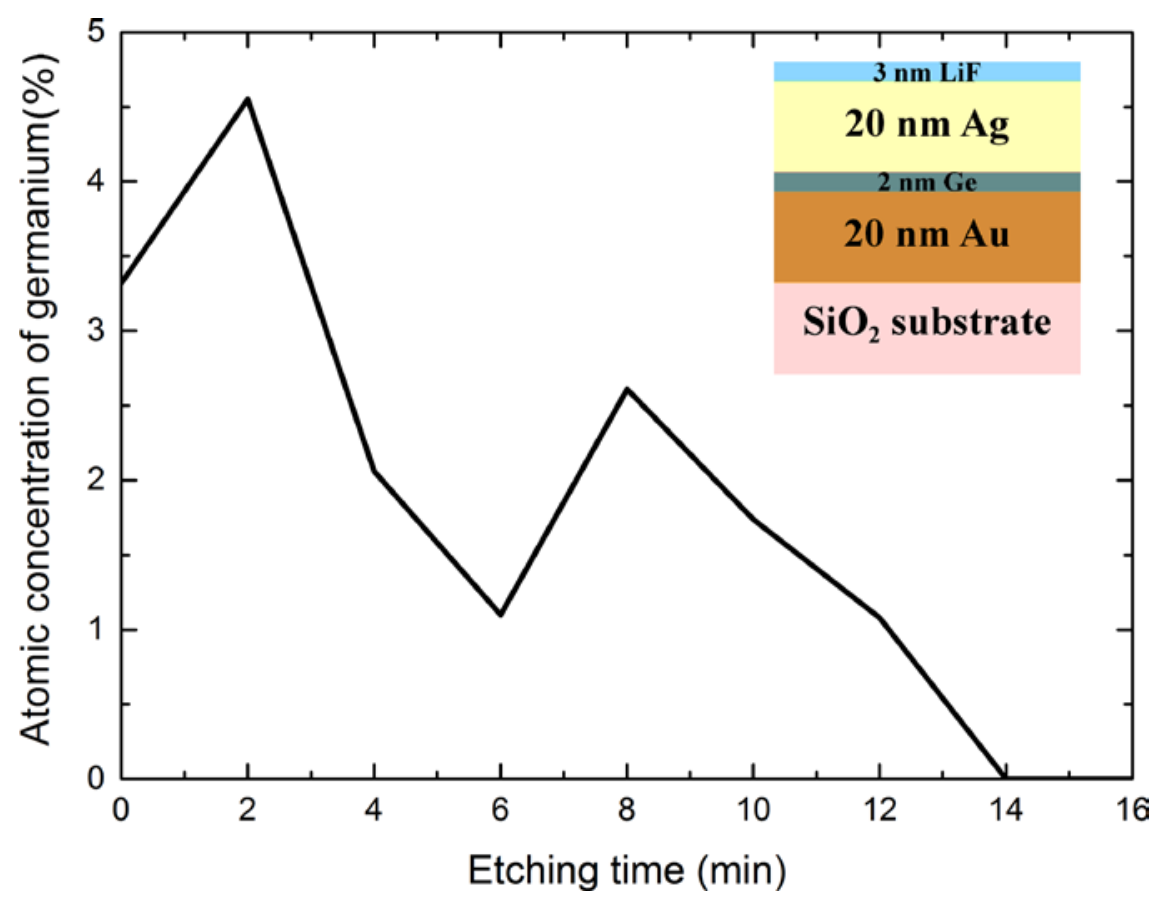

Figure 2. Atomic concentration profile of germanium atoms in the $\mathrm{Au} / \mathrm{Ge} / \mathrm{Ag}$ sandwich sample. Etching time is equivalent to subsurface depth. One minute of $\mathrm{Ar}^{+}$ion etching corresponds to removal of approximately $3 \mathrm{~nm}$ of the sample.

To verify whether inhibited segregation of germanium in an $\mathrm{Au} / \mathrm{Ge} / \mathrm{Ag}$ sandwich translates to differences in the optical domain, we have performed reflectivity measurements. Figure 3 presents the normal reflectance spectra of sandwich structures for different time periods after the fabrication of the samples. In this case, however, the metal layers have to be as thick as $50 \mathrm{~nm}$, so that the top metal layer is non-transparent. That way, the measurement result does not depend on the optical properties of the bottom metal layer. In the case of the $\mathrm{Ag} / \mathrm{Ge} / \mathrm{Ag}$ sample, where germanium is between two layers of $\mathrm{Ag}$, there is a noticeable time evolution of the reflectance curve. As time passes, the reflectance drops by nearly $10 \%$ in the range of 350 to $600 \mathrm{~nm}$. For instance, on the first day after deposition, the reflectance at $450 \mathrm{~nm}$ is $87.5 \%$, while after 25 days, it drops to $81 \%$. Moreover, the position of the minimum in the reflectance spectrum changes from $310 \mathrm{~nm}$ on the 1 st day after deposition to 312.5 on the 25th day. This correlates with the 2-nm redshift in the electron energy loss function maximum for Ge-wetted silver samples measured in an earlier work [38]. These effects imply the undisturbed occurrence of segregation of germanium atoms within the top Ag layer. For the sample where the bottom Ag layer has been replaced with $\mathrm{Au}$, these effects are also observable, but are much less intense-the reflectance 
at $450 \mathrm{~nm}$ drops only by 2 percentage points and the position of the maximum redshifts by only about $0.5 \mathrm{~nm}$. This is a clear indication that the segregation of germanium within the top Ag layer is inhibited. It is also worth noting that, for both samples, the curves after 25 days do not change much anymore, which suggests that the segregation process has completed.
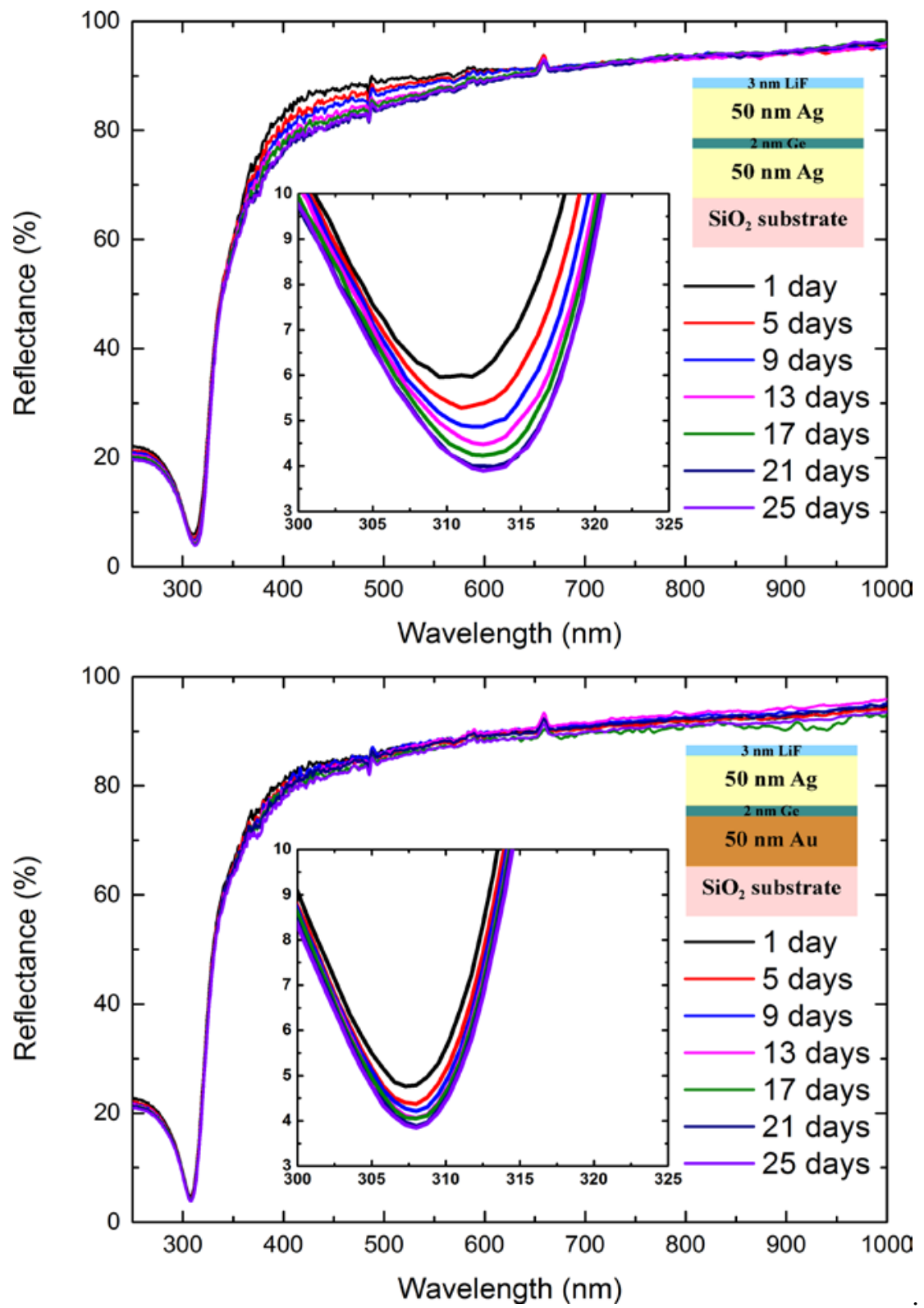

Figure 3. Reflectance spectra of sandwich-like structures where 2-nm-thick germanium film is deposited in between two 50-nm-thick Ag layers (top), and when the bottom Ag layer is replaced with Au (bottom). The insets present the enhanced fragment of the main graphs. The small kinks at 487 and $659 \mathrm{~nm}$ are measurement artifacts.

Both the XPS and the reflectivity measurements show that for the $\mathrm{Au} / \mathrm{Ge} / \mathrm{Ag}$ sample, germanium atoms segregate much slower than in the case of the $\mathrm{Ag} / \mathrm{Ge} / \mathrm{Ag}$ sample. This suggests that there is smaller energy benefit for Ge atoms segregating in Ag layers than in Au layers. This is consistent with thermodynamic theoretical considerations. One of the most famous models of surface segregation in 
binary (consisting of only two substances) systems is the model proposed by Wynblatt and Ku. In their model, the enthalpy of surface segregation is defined as follows [28,42]:

$$
\begin{aligned}
\Delta H^{\text {seg }}= & -\frac{24 \pi \zeta_{W} Y_{m} r_{W} r_{m}\left(r_{m}-r_{W}\right)^{2}}{3 \zeta_{W} r_{W}+4 Y_{m} r_{m}}+\left(\gamma_{m}-\gamma_{W}\right) A_{S} \\
& +2 \omega\left[z_{\text {lat }}\left(X_{m}^{b}-X_{m}^{S}\right)+z_{v}\left(X_{m}^{b}-0.5\right)\right]
\end{aligned}
$$

where $\zeta$ is the bulk modulus, $\mathrm{Y}$ is the shear modulus, $r$ is the atomic radius, $\gamma$ is the surface energy, $A_{S}$ is the area per atom available to minority atoms to segregate to, $z_{l a t} \mathrm{i} z_{v}$ in-plane and out-of-plane coordination numbers, $X$ is the atomic fraction, $\omega$ is the regular solution parameter specific for each binary system (since it depends on the nearest neighbor interaction energies), $W$ denotes the majority substance (in our case silver or gold), $m$ denotes the minority substance (in our case germanium, $b$ denotes the bulk phase and $S$ denotes the surface phase (the phase to which minority atoms segregate to, which in principle could also be grain boundaries). If the enthalpy value is negative, then the segregation process will occur.

The first term in the above equation, describing the release of elastic strain energy due to segregation, is always negative, regardless of the election of the majority and minority substances. Since silver and gold have similar atomic radii [47] as well as similar shear modulus [48], the difference in bulk moduli -200 GPa for gold vs 100 GPa for silver [48], leads to a 30\% difference in the values of this term. Taking the metallic radius $r_{W}=144 \mathrm{pm}$ for silver and gold [47] and a covalent radius $r_{m}=121 \mathrm{pm}$ for germanium [49,50] and getting the bulk and shear moduli values for $\mathrm{Ag}, \mathrm{Au} \mathrm{[48]}$ and Ge [51] we get $-6,175 \times 10^{-20} \mathrm{~J} /$ atom for the Ge-Ag system and $-8,085 \times 10^{-20} \mathrm{~J} /$ atom for the $\mathrm{Ge}-\mathrm{Au}$ system. Influence of the $\left(\gamma_{m}-\gamma_{W}\right) A_{S}$ term on the enthalpy of segregation depends strongly on the structural parameters of the system. Surface energy values for Ag and Au [52] as well as for Ge [53] vary depending on the crystallographic orientation. Thus, depending on the orientation, the value of $\left(\gamma_{m}-\gamma_{W}\right) A_{S}$ might be either negative or positive, thus contributing towards segregation or against it. Fortunately, both Ag and Au layers deposited directly on glass or silicon substrates, as well as on Ge wetting layers, grow in a 111 orientation relative to the substrate plane. Thus, we might expect Ge atoms that segregated to the surface to form the 111 structure, since Ge is in the same space group as $\mathrm{Ag}$ and $\mathrm{Au}$. In this case, the surface energy values need to be taken for the 111 surfaces for all elements. Thus, taking $\gamma_{G e}=1,06 \frac{J}{m^{2}}[53], \gamma_{A g}=1,12 \frac{J}{m^{2}}, \gamma_{A u}=1,61 \frac{J}{m^{2}}[52]$ gives $\left(\gamma_{G e}-\gamma_{A g}\right)=-0,06 \frac{J}{m^{2}}$ and $\left(\gamma_{G e}-\gamma_{A u}\right)=-0,55 \frac{J}{m^{2}}$.

Greater negative values of the first two terms in the discussed equation imply, as stated earlier, that there is smaller energy benefit for Ge atoms segregating in Ag layers than in Au layers. This would explain why in the case of $\mathrm{Au} / \mathrm{Ge} / \mathrm{Ag}$ sample, segregation of germanium is inhibited, while for the $\mathrm{Ag} / \mathrm{Ge} / \mathrm{Au}$ sample it is not. However, since the average grain size of Ag layers deposited on Ge films is more than twice smaller than the grain size of Au layers deposited on Ge films-9 $\mathrm{nm}$ for $\mathrm{Ag}$ [38] and $20 \mathrm{~nm}$ for $\mathrm{Au}$ [40] — the actual surface area available for the segregating Ge atoms might be larger in case of the Ag surface than in the case of the Au surface. Therefore, the value of the $\left(\gamma_{m}-\gamma_{W}\right) A_{S}$ term, as well as the value of the entropic contribution to the free enthalpy of segregation, might be actually greater for the silver layer than for the gold layer. This would explain why, even in the case of the $\mathrm{Au} / \mathrm{Ge} / \mathrm{Ag}$ sandwich structure, the segregation of Ge in Ag still occurs, and the highest concentration of germanium is observed near the surface rather than at the boundary of the Ag and Au layers. Analysis of the last term in this equation is more complicated and lies outside the scope of this article.

\section{Conclusions}

We have fabricated sandwich-like $\mathrm{Au} / \mathrm{Ge} / \mathrm{Ag}$ and $\mathrm{Ag} / \mathrm{Ge} / \mathrm{Ag}$ structures where 2-nm-thick films of Ge were deposited on top Au or Ag layers of 20 or $50 \mathrm{~nm}$ thickness and covered with correspondingly thick Ag nanolayers. Using XPS and optical reflectometry measurements, we have shown that the process of segregation of Ge atoms within the top Ag layer is inhibited when the bottom layer is made of gold, although segregation is not canceled completely. For better efficiency in canceling the 
segregation, we recommend using our approach in conjunction with covering the surface of the silver sample with an overlayer of $\mathrm{Al}_{2} \mathrm{O}_{3}$, as proposed by Wróbel et al. [19].

Supplementary Materials: The following are available online at http:/www.mdpi.com/2073-4352/10/4/262/s1.

Author Contributions: Conceptualization A.C.; methodology A.C.; software A.C. and M.T.; validation A.C. and T.S.; formal analysis A.C.; investigation A.C. and M.T.; resources A.C.; data curation A.C. and M.T.; writing-original draft preparation A.C.; writing—review and editing, T.S.; visualization A.C.; supervision T.S.; project administration T.S.; funding acquisition T.S. All authors have read and agreed to the published version of the manuscript.

Funding: This research received no external funding.

Conflicts of Interest: The authors declare no conflict of interest.

\section{References}

1. Aouani, H.; Wenger, J.; Gerard, D.; Rigneault, H.; Devaux, E.; Ebbesen, T.W.; Mahdavi, F.; Xu, T.; Blair, S. Crucial role of the adhesion layer on the plasmonic fluorescence enhancement. ACS Nano 2009, 3, 2043-2048. [CrossRef] [PubMed]

2. Chaturvedi, P.; Wu, W.; Logeeswaran, V.J.; Yu, Z.; Islam, M.S.; Wang, S.Y.; Williams, R.S.; Fang, N.X. A smooth optical superlens. Appl. Phys. Lett. 2010, 96, 043102. [CrossRef]

3. Melpignano, P.; Cioarec, C.; Clergereaux, R.; Gherardi, N.; Villeneuve, C.; Datas, L. E-beam deposited ultra-smooth silver thin film on glass with different nucleation layers: An optimization study for OLED micro-cavity application. Org. Electron. 2010, 11, 1111-1119. [CrossRef]

4. Boltasseva, A.; Atwater, H.A. Low-loss plasmonic metamaterials. Science 2011, 331, 290-291. [CrossRef] [PubMed]

5. Cioarec, C.; Melpignano, P.; Gherardi, N.; Clergereaux, R.; Villeneuve, C. Ultrasmooth silver thin film electrodes with high polar liquid wettability for OLED microcavity application. Langmuir 2011, 27, 3611-3617. [CrossRef]

6. Špačková, N.; Wrobel, P.; Bocková, M.; Homola, J. Optical biosensors based on plasmonic nanostructures: A review. Proc. IEEE 2016, 104, 2380-2408. [CrossRef]

7. Stefaniuk, T.; Olivier, N.; Belardini, A.; McPolin, C.P.T.; Sibilia, C.; Wronkowska, A.A.; Wronkowski, A.; Szoplik, T.; Zayats, A.V. Self-assembled silver-germanium nanolayer metamaterial with the enhanced nonlinear response. Adv. Opt. Mater. 2017, 5, 1700753. [CrossRef]

8. Zhao, G.; Shen, W.; Jeong, E.; Lee, S.-G.; Yu, S.M.; Bae, T.-S.; Lee, G.-H.; Han, S.Z.; Tang, J.; Choi, E.-A.; et al. Ultrathin silver film electrodes with ultralow optical and electrical losses for flexible organic photovoltaics. ACS Appl. Mater. Interfaces 2018, 10, 27510-27520. [CrossRef]

9. Mahapatro, A.K.; Scott, A.; Manning, A.; Janes, D.B. Gold surface with sub-nm roughness realized by evaporation on a molecular adhesion monolayer. Appl. Phys. Lett. 2006, 88, 151917. [CrossRef]

10. Oates, T.W.H.; Ryves, L.; Bilek, M.M.M. Dielectric functions of a growing silver film determined using dynamic in situ spectroscopic ellipsometry. Opt. Express 2008, 16, 2302-2314. [CrossRef]

11. Logeeswaran, V.J; Kobayashi, N.P.; Islam, M.S.; Wu, W.; Chaturvedi, P.; Fang, N.X.; Wang, S.Y.; Williams, R.S. Ultrasmooth silver thin films deposited with a germanium nucleation layer. Nano Lett. 2009, 9, 178-182. [CrossRef] [PubMed]

12. Liu, H.; Wang, B.; Leong, E.S.P.; Yang, P.; Zong, Y.; Si, G.; Teng, J.; Maier, S.A. Enhanced surface plasmon resonance on a smooth silver film with a seed growth layer. ACS Nano 2010, 4, 3139-3146. [CrossRef] [PubMed]

13. Ke, L.; Lai, S.C.; Liu, H.; Peh, C.K.N.; Wang, B.; Teng, J.H. Ultrasmooth silver thin film on PEDOT: PSS nucleation layer for extended surface plasmon propagation. ACS Appl. Mater. Interfaces 2012, 4, 1247-1253. [CrossRef] [PubMed]

14. Flötotto, D.; Wang, Z.M.; Jeurgens, L.P.H.; Bischoff, E.; Mittemeijer, E.J. Effect of adatom surface diffusivity on microstructure and intrinsic stress evolutions during Ag film growth. J. Appl. Phys. 2012, 112, 043503. [CrossRef] 
15. Formica, N.; Ghosh, D.S.; Carrilero, A.; Chen, T.L.; Simpson, R.E.; Pruneri, V. Ultrastable and atomically smooth ultrathin silver films grown on a copper seed layer. ACS Appl. Mater. Interfaces 2013, 5, 3048-3053. [CrossRef] [PubMed]

16. Siegfried, T.; Ekinci, Y.; Martin, O.J.F.; Sigg, H. Engineering metal adhesion layers that do not deteriorate plasmon resonances. ACS Nano 2013, 7, 2751-2757. [CrossRef] [PubMed]

17. Stefaniuk, T.; Wróbel, P.; Górecka, E.; Szoplik, T. Optimum temperature for deposition of ultrasmooth silver nanolayers. Nanoscale Res. Lett. 2014, 9, 153-161. [CrossRef]

18. Stefaniuk, T.; Wróbel, P.; Trautman, P.; Szoplik, T. Ultrasmooth metal nanolayers for plasmonic applications: Surface roughness and specific resistivity. Appl. Opt. 2014, 53, B237-B241. [CrossRef]

19. Wróbel, P.; Stefaniuk, T.; Trzcinski, M.; Wronkowska, A.A.; Wronkowski, A.; Szoplik, T. Ge wetting layer increases ohmic plasmon losses in Ag film due to segregation. ACS Appl. Mater. Interfaces 2015, 7, 8999-9005. [CrossRef]

20. Leandro, L.; Malureanu, R.; Rozlosnik, N.; Lavrinienko, A. Ultrathin, ultrasmooth gold layer on dielectrics without the use of additional metallic adhesion layers. ACS Appl. Mater. Interfaces 2015, 7, 5797-5802. [CrossRef]

21. Sukham, J.; Takayama, O.; Lavrinenko, A.V.; Malureanu, R. High-quality ultrathin gold layers with an APTMS adhesion for optimal performance of surface plasmon polariton-based devices. ACS Appl. Mater. Interfaces 2017, 9, 25049-25056. [CrossRef] [PubMed]

22. Krayer, L.J.; Kim, J.; Munday, J.N. Near-perfect absorption throughout the visible using ultra-thin metal films on index-near-zero substrates. Opt. Mater. Express 2019, 9, 330-338. [CrossRef]

23. Cancellieri, C.; Klyatskina, E.; Chiodi, M.; Janczak-Rusch, J.; Jeurgens, L.P.H. The effect of interfacial Ge and RF-bias on the microstructure and stress evolution upon annealing of Ag/AlN multilayers. Appl. Sci. 2018, 8, 2403. [CrossRef]

24. Ariosa, D.; Cancellieri, C.; Araullo-Peters, V.; Chiodi, M.; Klyatskina, E.; Janczak-Rusch, J.; Jeurgens, L.P.H. Modeling of interface and internal disorder applied to XRD analysis of Ag-based nano-multilayers. ACS Appl. Mater. Interfaces 2018, 10, 20938-20949. [CrossRef]

25. Parmigiani, F.; Kay, E.; Huang, T.; Perrin, J.; Jurich, M.; Swalen, J.D. Optical and electrical properties of thin silver films grown under ion bombardment. Phys. Rev. B Condens. Matter Mater. Phys. 1986, 33, 879-888. [CrossRef]

26. Tsuda, Y.; Omoto, H.; Tanaka, K.; Ohsaki, H. The underlayer effects on the electrical resistivity of Ag thin film. Thin Solid Films 2006, 502, 223-227. [CrossRef]

27. Yakubovsky, D.I.; Arsenin, A.V.; Stebunov, Y.V.; Fedyanin, D.Y.; Volkov, V.S. Optical constants and structural properties of thin gold films. Opt. Express 2017, 25, 25574-25587. [CrossRef]

28. Wynblatt, P.; Ku, R.C. Surface energy and solute strain energy effects in surface segregation. Surf. Sci. 1977, 65, 511-531. [CrossRef]

29. Seah, M.P. Quantitative prediction of surface segregation. J. Catal. 1979, 57, 450-457. [CrossRef]

30. Wachs, L.; Miller, T.; Chiang, T.C. Evidence for germanium segregation on thin films of Ag on Ge(111). Phys. Rev. B 1986, 33, 8870-8873. [CrossRef]

31. Olesinski, R.W.; Abbaschian, G.J. The Ag-Ge (silver germanium) system. Bull. Alloy Phase Diagr. 1988, 9, 58-64. [CrossRef]

32. Herzig, C.; Divinski, S.V. Grain boundary diffusion in metals: Recent developments. Mater. Trans. 2003, 44, 14-27. [CrossRef]

33. Wynblatt, P.; Chatain, D. Anisotropy of segregation at grain boundaries and surfaces. Metall. Mater. Trans. A 2006, 37, 2595-2620. [CrossRef]

34. Wynblatt, P. Interfacial segregation effects in wetting phenomena. Annu. Rev. Mater. Res. 2008, 38, $173-196$. [CrossRef]

35. Lončarić, M.; Sancho-Parramon, J.; Pavlovič, M.; Zorc, H.; Dubček, P.; Turković, A.; Bernstorff, S.; Jakopič, G.; Haase, A. Optical and structural characterization of silver islands films on glass substrates. Vacuum 2009, 84, 188-192. [CrossRef]

36. Stefaniuk, T.; Ciesielski, A.; Wrobel, P.; Wronkowska, A.A.; Wronkowski, A.; Skowronski, L.; Szoplik, T. Optical parameters of $10 \mathrm{~nm}$ to $100 \mathrm{~nm}$ thick silver films. Rom. Rep. Phys. 2015, 67, 1331-1333.

37. Ciesielski, A.; Skowronski, L.; Trzcinski, M.; Górecka, E.; Kierdaszuk, J.; Szoplik, T. Growth model and structure evolution of Ag films deposited on Ge. Beilstein J. Nanotechnol. 2018, 9, 66-76. [CrossRef] 
38. Ciesielski, A.; Skowronski, L.; Trzcinski, M.; Szoplik, T. Controlling the optical parameters of self-assembled silver films with wetting layers and annealing. Appl. Surf. Sci. 2017, 421, 349-356. [CrossRef]

39. Ciesielski, A.; Skowronski, L.; Pacuski, W.; Szoplik, T. Permittivity of Ge, Te and Se thin films in the 200-1500 nm spectral range. Predicting the segregation effects in silver. Mater. Sci. Semicond. Process. 2018, 81, 64-67. [CrossRef]

40. Ciesielski, A.; Skowronski, L.; Trzcinski, M.; Górecka, E.; Trautman, P.; Szoplik, T. Evidence of germanium segregation in gold thin films. Surf. Sci. 2018, 674, 73-78. [CrossRef]

41. Ciesielski, A.; Skowronski, L.; Trzcinski, M.; Górecka, E.; Pacuski, W.; Szoplik, T. Interaction of Te and Se interlayers with Ag or Au nanofilms in sandwich structures. Beilstein J. Nanotechnol. 2019, 10, 238-246. [CrossRef] [PubMed]

42. Lejček, P. Grain Boundary Segregation in Metals; Springer Science \& Business Media: Berlin, Germany, 2010.

43. Mehrer, H. Diffusion in Solids: Fundamentals, Methods, Materials, Diffusion-Controlled Processes; Springer Science \& Business Media: Berlin, Germany, 2007.

44. Paul, A.; Laurila, T.; Vuorinen, V.; Divinski, S.V. Thermodynamics, Diffusion and the Kirkendall Effect in Solids; Springer International Publishing: Cham, Switzerland, 2014.

45. Lejček, P.; Hofmann, S. On the relationship between entropy and enthalpy of grain boundary segregation. Interface Sci. 2001, 9, 221-230. [CrossRef]

46. Lejček, P.; Hofmann, S. Thermodynamics of grain boundary segregation and applications to anisotropy, Compensation Effect and Prediction. Crit. Rev. Solid State 2008, 33, 133-163. [CrossRef]

47. Greenwood, N.N.; Earnshaw, A. Chemistry of the Elements; Butterworth-Heinemann: Oxford, England, 1997.

48. The Photographic Periodic Table of the Elements. Available online: https://periodictable.com/ (accessed on 17 March 2020).

49. Cordero, B.; Gómez, V.; Platero-Prats, A.E.; Revés, M.; Echeverría, J.; Cremades, E.; Barragán, F.; Alvarez, S. Covalent radii revisited. Dalton Trans. 2008, 21, 2832-2838. [CrossRef] [PubMed]

50. Pyykkö, P.; Atsumi, M. Molecular Single-Bond Covalent Radii for Elements 1-118. Chem. Eur. J. 2009, 15, 186-197. [CrossRef] [PubMed]

51. Mechanical Properties, Elastic Constants, Lattice Vibrations of Germanium (Ge). Available online: http: //www.ioffe.ru/SVA/NSM/Semicond/Ge/mechanic.html (accessed on 17 March 2020).

52. Skriver, H.L.; Rosengaard, N.M. Surface energy and work function of metals. Phys. Rev. B 1992, 46, 7157-7168. [CrossRef]

53. Jaccodine, R.J. Surface Energy of Germanium and Silicon. J. Electrochem. Soc. 1963, 110, 524-527. [CrossRef] 